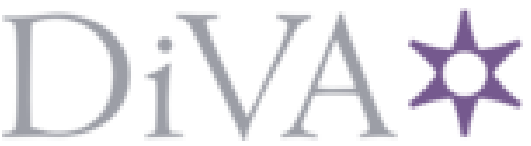

http://www.diva-portal.org

Postprint

This is the accepted version of a paper presented at 2020 International Conference on Probabilistic Methods Applied to Power Systems (PMAPS).

Citation for the original published paper:

Molina Gomez, A., Gomes Guerreiro, G M., Wiklund, H., Lindstén, J., Nalini

Ramakrishna, S K. et al. (2020)

Emergency power flow re-routing in a distribution system by using dynamic line rating In:

N.B. When citing this work, cite the original published paper.

Permanent link to this version:

http://urn.kb.se/resolve?urn=urn:nbn:se:kth:diva-293165 


\section{Emergency power flow re-routing in a distribution system by using dynamic line rating}

\author{
$1^{\text {st }}$ Andrea Molina Gómez, \\ Gabriel Miguel Gomes Guerreiro, \\ Hannes Wiklund, Johanna Lindstén, \\ Sindhu Kanya Nalini Ramakrishna \\ School of Electrical Engineering and \\ Computer Science \\ KTH Royal Institute of Technology \\ Stockholm, Sweden
}

\author{
$2^{\text {nd }}$ Kateryna Morozovska \\ Heimdall Power AS \\ Oslo, Norway \\ kateryna@heimdallpower.com, and \\ Dep. of Electromagnetic Engineering \\ School of Electrical Engineering and \\ Computer Science \\ KTH Royal Institute of Technology \\ Stockholm, Sweden \\ kmor@kth.se
}

\author{
$3^{\text {rd }}$ Patrik Hilber \\ Dep. of Electromagnetic Engineering \\ School of Electrical Engineering and \\ Computer Science \\ KTH Royal Institute of Technology \\ Stockholm, Sweden \\ hilber@kth.se
}

\begin{abstract}
Dynamic rating is a technology which allows loading power lines above their rated limits. More often, dynamic rating is used to transport new power and connect additional generators to the grid using existing infrastructure. However, this study explores the possibility to use dynamic rating for improving the security of supply and assisting fast reconnection of disconnected customers during emergency and fault situations occurring at other lines. DLR allows improving power system reliability during emergency conditions using Optimal Power Flow (OPF), which additionally helps to minimize costs of system operation. Large costs involving investment for new infrastructure and penalties for interruptions in the power supply can be considerably reduced by implementing DLR. Also, DLR can improve the reliability of the system by providing real-time information on the status of power lines. Using Optimal Power Flow ensures that the lines loading, bus voltage magnitudes and angles as well as generation injections are within the acceptable limits as per the utility regulations. Faults are modelled as cases when one of the lines becomes disconnected. The bottlenecks in the system during post-fault situations are identified to determine optimal lines in the system on which DLR could be implemented.
\end{abstract}

Index Terms-dynamic line rating, power system reliability, optimal power flow, security of supply

\section{INTRODUCTION}

Conventionally, the maximum line loading limit known as line rating is calculated considering a high conductor temperature, high solar irradiance and low wind speed. However, favourable weather conditions can allow more current through the conductor compared to the traditional line rating. This technology, where the ampacity of the conductor is recalculated continuously by considering the actual weather and physical conditions of the conductor is known as Dynamic Line Rating (DLR). DLR is an operational philosophy that enables the increase in the current-carrying capability of the overhead line (OHL), without compromising the safety. Studies have shown that the real capability of OHL's is considerably higher than the static ratings for many operating conditions during favourable weather conditions [1] [2] [3].
Increasing electricity demand results in a need for upgrading the existing grid involving substantial investment costs and time. Moreover, the system operators are penalized for power supply interruptions, and the penalty depends on the duration of the outage. Therefore, the operators must ensure reliable power supply to the consumers even during fault conditions in the grid. These challenges of catering the increasing demand with existing grid infrastructure, ensuring a high degree of reliability have to be addressed.

The unused capacity of the transmission lines between the static rating and the real ampacity limit calculated using DLR can relieve network congestion, ensuring more reliable operation and power delivery. In the event of a fault, DLR could be used for optimizing power flow passage using available transmission lines, which in turn could reduce the operation costs.

Previously, several studies have been carried out on the topic of power system reliability after DLR application [3] [4] and a few studies have been done on improving system redundancy using DLR [2]. For example, papers [2] and [5] are looking at the impact of DLR on the reliability of the power network. In [2] authors a make general overview of possible DLR benefits to the system, while [5] reaches the conclusion that DLR might not be able to provide significant benefits to the network reliability, however, the conclusions are based only on one grid. In [6], the impact of increased thermal overload duration and emergency loading on power lines is addressed. In [6] authors show that increased duration of overload can improve network flexibility during emergency scenarios; however, it might result in fast ageing of the conductor.

After considering existing findings, authors see a need for a more detailed case study, which would show pros and cons of using DLR as an emergency measure to reduce the impact of faults on system availability and energy not supplied (ENS). The fault is always considered to be cleared, taking into account that protection systems and circuit breakers do not influence the reliability calculations. After the fault occurs and 
the system reaches steady-state, the power flow is optimized using dynamically rated lines and optimal power flow (OPF), which allows reducing the cost of operation and cost of interruption. Initially, OPF is carried for various faults in the given system, to determine the priority of the lines in the system where DLR could be implemented. The results obtained from OPF for the cases with DLR will help in deciding the optimal number of lines on which DLR can be installed in the system both from a technical and economic point of view.

This paper shows two methods of determining the optimal location of implementing DLR in a given system considering possible budget constraints that may be present in lower voltage levels.

\section{Methodology}

This section describes the method used for calculating line ratings and reliability indices in this study. The formulation of the optimal power flow and two algorithms used for this study are also introduced.

\section{A. Dynamic Line Rating}

IEEE [7] and CIGRÉ [8] standards are available for calculating the Dynamic Line Rating for overhead lines. In this case, the IEEE-738 standard is used.

According to [7], the steady-state heat balance is defined as per equation (1).

$$
q_{c}+q_{r}-q_{s}=I^{2} R\left(T_{a v g}\right)
$$

where $q_{c}$ is the convection heat loss rate per unit length, $[\mathrm{W} / \mathrm{m}] ; q_{r}$ is the radiated heat loss rate per unit length, [W/m]; $q_{s}$ is the heat gain rate from sun, $[\mathrm{W} / \mathrm{m}] ; I$ is the current in the conductor, [A]; $R\left(T_{a v g}\right)$ is the $\mathrm{AC}$ resistance of the conductor at temperature $T_{\text {avg }},[\Omega]$.

By calculating the heat losses and heat gain from the sun, the conductor current can be calculated. In the subsequent subsections, each of the heat losses is explained in detail.

Convective heat loss is divided into two types in the IEEE standard: natural convection and forced convection. The convention adopted is to calculate both losses depending on wind speed and to consider the greater of the two values. The forced convection loss is calculated when the wind speed is greater than zero, and the natural convection loss is calculated when the wind speed is zero. The magnitude of both heat losses is a function of the Reynolds number. Firstly, the forced convection heat loss is calculated. There are two equations to calculate this loss (2) and (3). The standard recommends calculating the forced convective loss using two separate equations and to consider the larger of the two calculated values.

$$
\begin{array}{r}
q_{c 1}=K_{\text {angle }}\left[1.01+1.35 N_{R e}^{0.52}\right] k_{f}\left(T_{s}-T_{a}\right),[W / m] \\
q_{c 2}=K_{\text {angle }} 0.754 N_{R e}^{0.6} k_{f}\left(T_{s}-T_{a}\right),[W / m]
\end{array}
$$

where $K_{\text {angle }}$ is the wind direction factor; $N_{R e}$ is Reynolds number; $k_{f}$ is the thermal conductivity of air at temperature $T_{\text {film }} ; T_{\text {film }}$ is the mean of the surface conductor temperature $\left(T_{s}\right)$ and the ambient temperature $\left(T_{a}\right)$.
Secondly, the natural convection heat loss is calculated as in (4)

$$
q_{c n}=3.645 \rho_{f}^{0.5} D_{0}^{0.75}\left(T_{s}-T_{a}\right)^{1.25},[W / m]
$$

where $\rho_{f}$ is the air density; $D_{0}$ is the conductor diameter.

Radiative heat loss is described by the Stefan-Boltzmann law and is dependent primarily on the difference in temperature between the conductor and its surroundings and can be computed using (5).

$$
q_{r}=17.8 D_{0} \varepsilon\left[\left(\frac{T_{s}+273}{100}\right)^{4}-\left(\frac{T_{a}+273}{100}\right)^{4}\right],[W / m]
$$

where $\varepsilon$ is emissivity of conductor material.

The heating of the conductor due to solar radiation is calculated using (6) [7].

$$
q_{s}=\alpha Q_{s e} \sin (\Theta) \cdot A^{\prime},[W / m]
$$

where $\alpha$ is the solar absorptivity; $Q_{\text {se }}$ is the total solar and sky radiated heat intensity corrected for elevation; $\Theta$ is the effective angle of incidence of the sun's rays; $A^{\prime}$ is the projected area of conductor.

\section{B. AC Optimal Power Flow}

The main goal of the system operator is to minimize the cost of operation along with ensuring the security of supply. This challenge can be addressed by solving the Optimal Power Flow (OPF).

The important step in the OPF is the problem formulation, which involves the determination of the variables, constraints and objective function. The primary objective function is to minimize the cost of operation of the power system subjected to the AC power flow constraints [9].

The optimization vector $x$ containing bus angles, bus voltages, real and reactive power injections of the generator can be represented, as shown in equation (7).

$$
x=\left[\begin{array}{c}
\theta \\
V_{m} \\
P_{g} \\
Q_{g}
\end{array}\right]
$$

The main objective function and constraints of AC Optimal Power Flow are given in (8a) and (8b), (8c), (8d) respectively.

$$
\begin{array}{cl}
\min _{\Xi} & f(x) \\
\text { s.t. } & g(x)=0 \\
& h(x) \leq 0 \\
& x_{\min } \leq x \leq x_{\max }
\end{array}
$$

where $f(x)$ is a function involving cost of generation and cost of energy not served; $g(x)$ represents the power balance equations; $h(x)$ represents upper limit for the branch and transformer flows; $x_{\min }$ and $x_{\max }$ represent the limits for bus angles, bus voltages, real and reactive power injections of the generator [10]. 


\section{Reliability in Distribution Systems}

The performance of the distribution system depends on the generation and transmission system. However, the analysis of a distribution system considering the transmission system becomes very complex; therefore, in this study distribution system is considered as a separate entity [11].

On the distribution level, reliability is often quantified in terms of customer interruptions [12]. Some widely used indices are:

- System Average Interruption Frequency Index (SAIFI) as to how often customer interruptions occur compared to the number of customers:

$$
S A I F I=\frac{\sum_{i} \lambda_{i} N_{i}}{\sum_{i} N_{i}}
$$

where $\lambda_{i}$ is the failure rate; $N_{i}$ is the number of customers for location $i$.

- Energy Not Supplied (ENS) as for the total amount of energy not supplied per year:

$$
E N S=L d S h \cdot h
$$

where $L d S h$ is the curtailed load, [MW]; $h$ is the duration of interruption.

In order to compare and evaluate the results, reliability indices total ENS and total SAIFI are used. (9) and (10) are redefined to compute the total ENS for each line failure according to (11) and the total SAIFI for each line failure according to (12), considering the total load of the system equal to 199 MW.

$$
\text { Total } E N S_{\text {line }}=L d S h \cdot p_{f} \cdot l \cdot \text { repair time }
$$

where $p_{f}$ is the probability of failure per year and per km line length; $l$ is the line length, [m].

$$
\text { Total SAIF } I_{\text {line }}=\frac{L d S h}{\text { total load of the system }} \times p_{f} \cdot l
$$

For calculating the reliability indices, some assumptions are made: $p_{f}=0.064$ [failures $/(\mathrm{km} \cdot$ years $)$ ] and repair time $=$ 1.11 [hours/failure] [13]. The probability of failure is assumed to depend on the length of the line. The cost of loss of load is equal to $43 \mathrm{SEK} / \mathrm{kWh}$ [13]. Total ENS $S_{\text {line }}$ and Total $S A I F I_{\text {line }}$ for each possible line failure are summed to get the Total ENS and Total SAIFI.

\section{Algorithms}

Two algorithms are developed based on the same selection criteria. The selection criteria used for determining the best locations for the placement of DLR is based on identifying the lines, which are the most congested during contingency in the system. If more than one line is congested for the same number of times during different fault conditions, the line with the highest average loading is selected.

Lines that are loaded to more than $80 \%$ compared to the static rating are considered to be most congested. Both algorithms presented below are designed based on the aforementioned criteria.

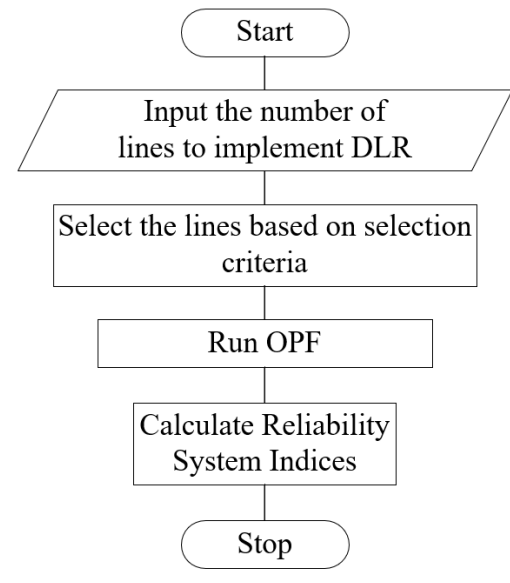

Fig. 1. Flowchart describing the process of algorithm 1.

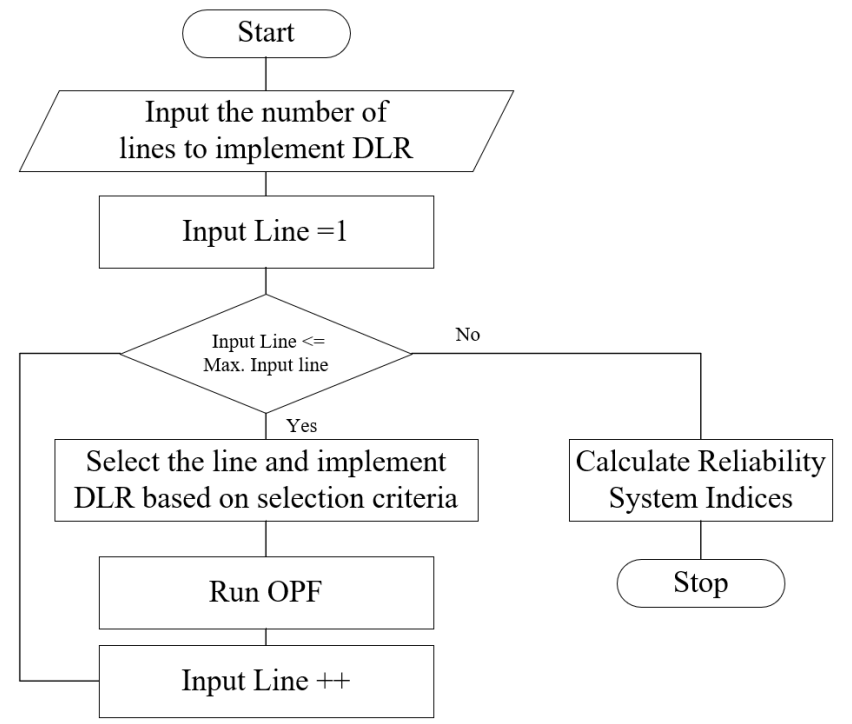

Fig. 2. Flowchart describing the process of algorithm 2.

The first algorithm involves selecting the lines based on selection criteria and choosing the optimal number of lines on which DLR should be implemented as input. The OPF is executed with DLR on a selected number of lines, and reliability system indices are calculated. The first algorithm is shown in Fig. 1. The second algorithm is similar to the first algorithm. However, the DLR is first implemented on the most congested line based on selection criteria, and then OPF is executed with DLR implemented on this line. The above procedure is repeated until DLR is implemented on the optimal number of lines. Finally, the reliability system indices are calculated. The second algorithm is presented in Fig. 2. Algorithms from Fig. 1 and 2 are used to test the test system presented in Section III and the resulting outcome is discussed in Section IV.

\section{CASe Study}

In the subsections below provide a brief description of the simulated system topology used in the study. 


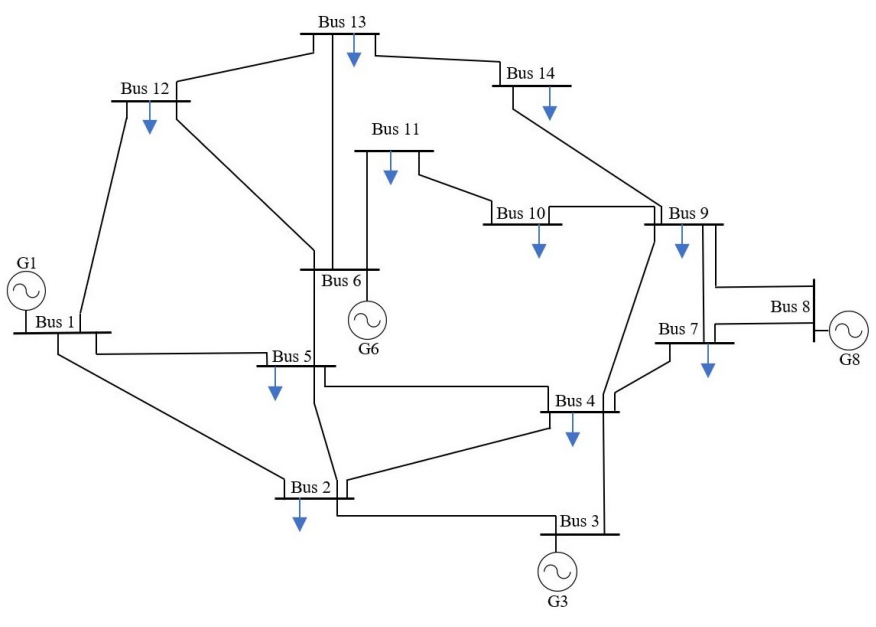

Fig. 3. Topology of the test system

\section{A. System Topology}

The test system used in the simulations is built to resemble the operation of a congested $22 \mathrm{kV}$ distribution system. For this, the IEEE 14 Bus System [14] is modified to have congestion in the system. The original IEEE 14 bus system has two different voltage levels, which are often critical from a reliability perspective. Therefore, to facilitate complex analysis of where to implement DLR, the system is modified to have a uniform voltage level and loads. Generation units are also distributed in a different manner to provide close to nominal line rating for most of the branches.

The modifications to the IEEE system can be summarised as:

- The transformers have been removed from the original system. This is done in order to obtain a uniform MV system and therefore achieve similar constraints for OHL and cables and uniform reliability indices [13].

- The impedances and capacitances of the lines are modified according to the actual line parameters provided in [15].

- Loads are added to all the buses excluding the generator buses in order to model load shedding.

- Loads and generation capacities are adjusted to ensure that the majority of the lines are close to their rated capacity. The cost of generation is assumed to be equal for all generators.

The topology of the constructed test system is depicted in Fig. 3, where the blue arrows represent the loads connected directly to the buses, and the sinusoidal sources represent the fours generation points in the system. The lines are modelled as aluminium steel-reinforced conductors. Initially, OPF calculations are performed considering arbitrary values for line parameters in the test system. The type and length of lines in [15] are adjusted according to the steady-state currents obtained from OPF results.

\section{B. Tests performed}

The results are obtained considering a set of sensitivity analyses of the main parameters that influence the performance of DLR in this system. The four main analyses performed are:

1) Influence of the variation in the wind speed. The wind speed is varied maintaining the rest of the parameters constant, i.e. temperature $=-8^{\circ} \mathrm{C}$, overloading percentage limit $=180 \%$ and a number of lines with DLR $=3$. Three different wind speeds are used for this analysis: $0.6 \mathrm{~m} / \mathrm{s}, 3 \mathrm{~m} / \mathrm{s}$ and $10 \mathrm{~m} / \mathrm{s}$. The wind speed $0.6 \mathrm{~m} / \mathrm{s}$ is used due to it being a common wind speed used for calculating static thermal ratings of transmission lines. The wind speeds 3 and $10 \mathrm{~m} / \mathrm{s}$ are used since they represent medium and high wind speeds in the area based on weather data. [16] The wind direction is kept constant at $90^{\circ}$. For each wind speed, the analysis is carried out using Algorithm 1 and Algorithm 2.

2) Influence of the variation in the ambient temperature. The ambient temperature is varied while maintaining the rest of the parameters constant, i.e. wind speed $=0.6 \mathrm{~m} / \mathrm{s}$, overloading percentage limit $=180 \%$ and $\mathrm{a}$ number of lines with DLR $=3$. Two different scenarios are studied: a winter scenario with a temperature of $-8^{\circ} \mathrm{C}$ and a summer scenario with a temperature of $11^{\circ} \mathrm{C}$. An additional case is also carried out considering the ambient temperature in the winter scenario and with DLR implemented on all of the 22 lines.

3) Influence of the variation considering an increase in the capacity of lines with DLR (overloading percentage). The overloading percentage limitation of the lines is varied while maintaining the rest of the parameters constant, i.e. wind speed $=0.6 \mathrm{~m} / \mathrm{s}$, temperature $=-8^{\circ} \mathrm{C}$ and number of lines with DLR $=3$. Five different scenarios/limitations are studied, and the analysis is carried for both Algorithms: 120\%, 140\%, 160\%, 180\% and $200 \%$, i.e. $20,40,60,80$ and $100 \%$ above the nominal static rating of the line. An additional case is also carried out considering an overloading percentage of $200 \%$ and with DLR implemented on 22 lines.

4) Influence of the variation in the number of lines on which DLR is implemented. The number of lines on which DLR is implemented is varied while maintaining the rest of the parameters constant, i.e. wind speed $=0.6$ $\mathrm{m} / \mathrm{s}$, temperature $=-8^{\circ} \mathrm{C}$ and overloading percentage $=180 \%$. The analysis is carried out considering DLR implemented on 3, 9, 15 and 22 number of lines respectively for each algorithm.

\section{RESULTS}

For comparison of the results from the different test case, the base scenario is defined with wind speed equal to $0.6 \mathrm{~m} / \mathrm{s}$ and ambient temperature equal to $-8{ }^{\circ} \mathrm{C}$. The actual capacity limit calculated by DLR is set at $180 \%$ compared to the static rating, and DLR is installed in 3 lines.

\section{A. Influence of the variation in the wind speed}

The wind speed variation has resulted in an outcome where higher wind speeds provided the better performance of the power system in terms of the calculated reliability indices as 


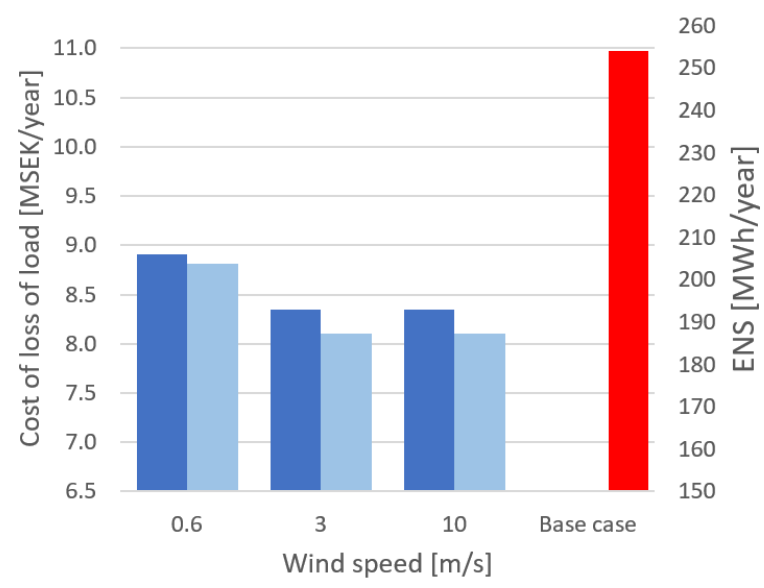

Algorithm 1 Algorithm 2 Base case

Fig. 4. Wind speed sensitivity

TABLE I

EFFECT OF WIND SPEED ON RESULT

\begin{tabular}{|c|c|c|c|}
\hline Cases & $\begin{array}{c}\text { Total ENS } \\
\text { [MWh/year] }\end{array}$ & $\begin{array}{l}\text { Total SAIFI } \\
\text { [f/year/customer] }\end{array}$ & $\begin{array}{c}\text { Interruption Cost } \\
\text { [SEK/year] }\end{array}$ \\
\hline Base case & 254 & 1.147 & 10921962 \\
Al. $\& 0.6 \mathrm{~m} / \mathrm{s}$ & 205.93 & 0.930 & 8855109 \\
Al. $\& 1 \mathrm{~m} / \mathrm{s}$ & 200.63 & 0.906 & 8627031 \\
Al. $\& 3 \mathrm{~m} / \mathrm{s}$ & 192.94 & 0.871 & 8296523 \\
Al. \& \& $10 \mathrm{~m} / \mathrm{s}$ & 192.94 & 0.871 & 8296523 \\
Al. 2 \& $0.6 \mathrm{~m} / \mathrm{s}$ & 203.88 & 0.920 & 8766637 \\
Al. 2 \& 1 m/s & 197.35 & 0.891 & 8485978 \\
Al. 2 \& $3 \mathrm{~m} / \mathrm{s}$ & 187.35 & 0.846 & 8056217 \\
Al. 2 \& $10 \mathrm{~m} / \mathrm{s}$ & 187.35 & 0.846 & 8056217 \\
22 lines \& $10 \mathrm{~m} / \mathrm{s}$ & 171.24 & 0.773 & 7363453 \\
\hline
\end{tabular}

presented in Fig. 4 and Table I. It is also visible that the positive effect of an increasing wind is slightly saturated above $3 \mathrm{~m} / \mathrm{s}$.

\section{B. Influence of the variation in the ambient temperature}

In analysing the influence of ambient temperature, two different scenarios have been evaluated, one summer scenario and one winter scenario. The resulting reliability indices are presented in Fig. 5 and Table II.

$C$. Influence of the variation considering increase in the capacity of lines with DLR (overloading percentage)

The sensitivity analysis of using different capacity limits when applying DLR is required to verify the results. These results are presented in Fig. 6 and Table III, where instead of the base case, a system-wide implementation of DLR is used as reference. Here it can also be observed that increasing the

TABLE II

EFFECT OF AMBIENT TEMPERATURE ON RESULTS.

\begin{tabular}{|c|c|c|c|}
\hline Cases & $\begin{array}{c}\text { Total ENS } \\
\text { [MWh/year] }\end{array}$ & $\begin{array}{c}\text { Total SAIFI } \\
\text { [f/year/customer] }\end{array}$ & $\begin{array}{l}\text { Cost } \\
\text { [SEK/year] }\end{array}$ \\
\hline Base case & 254.00 & 1.1466 & 10921962 \\
Al. 1 \& winter & 205.93 & 0.93 & 8855109 \\
Al. 1 \& summer & 203.88 & 0.92 & 8766637 \\
Al. 2 \& winter & 215.55 & 0.97 & 9268436 \\
Al. 2 \& summer & 215.13 & 0.97 & 9250585 \\
22 lines \& winter & 188.99 & 0.85 & 8126655 \\
\hline
\end{tabular}

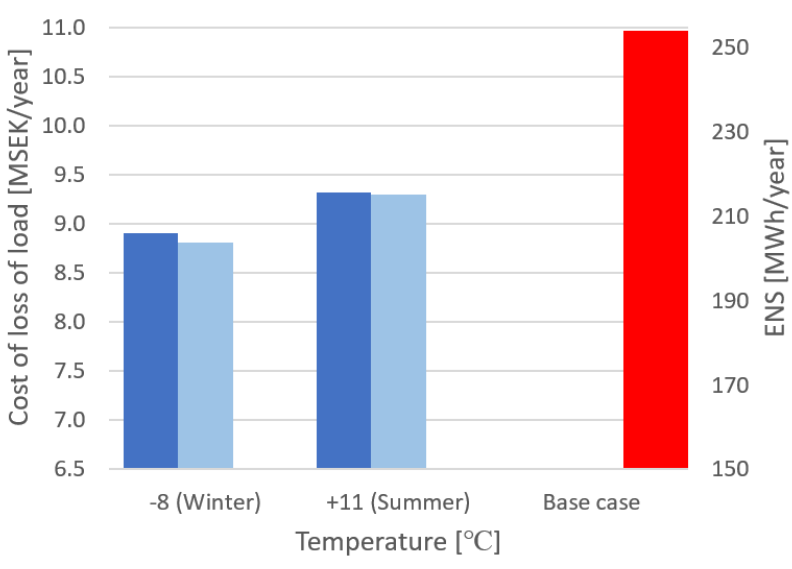

- Algorithm 1 Algorithm 2

Fig. 5. Temperature sensitivity

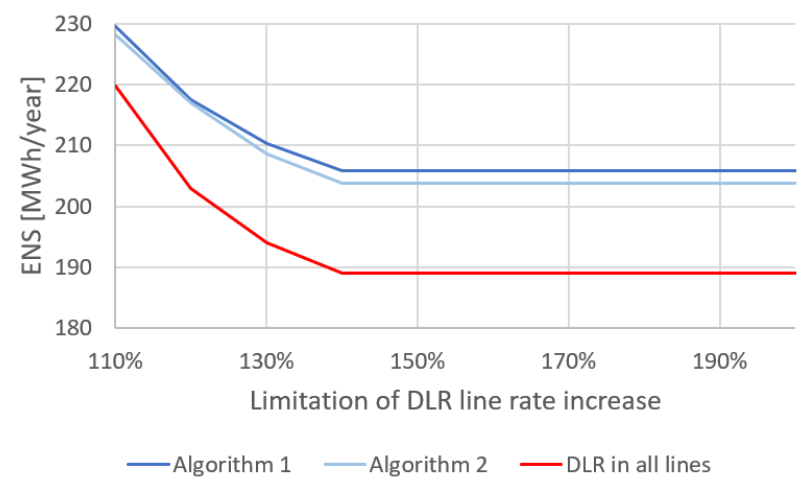

Fig. 6. Imposed capacity increase sensitivity

capacity is only effective up to a certain level. Afterwards, other system limitations, such as over-voltages act preventatively.

\section{Influence of the number of dynamically rated lines}

Lastly, the sensitivity regarding the number of lines with DLR installed has been analyzed. The same trend as in the earlier analyses can be observed here in that increasing the number of lines with DLR is only effective to a certain level. The effectiveness per line with DLR also installed strongest at the first few lines to then level out.

TABLE III

EFFECT OF OVERLOADING PERCENTAGE ON RESULTS

\begin{tabular}{|c|c|c|}
\hline Cases & $\begin{array}{l}\text { Total ENS } \\
\text { [MWh/year }]\end{array}$ & $\begin{array}{c}\text { Total SAIFI } \\
\text { [f/year/customer] }\end{array}$ \\
\hline Base & 254.00 & 1.147 \\
Al. 1 \& 120\% & 217.52 & 0.982 \\
Al. 1 \& 140\% & 205.93 & 0.930 \\
Al. 1 \& 160\% & 205.93 & 0.930 \\
Al. 1 \& 180\% & 205.93 & 0.930 \\
Al. 1 \& 200\% & 205.93 & 0.930 \\
Al. 2 \& 120\% & 217.01 & 0.980 \\
Al. 2 \& 140\% & 203.88 & 0.920 \\
Al. 2 \& 160\% & 203.88 & 0.920 \\
Al. 2 \& 180\% & 203.88 & 0.920 \\
Al. 2 \& 200\% & 203.88 & 0.920 \\
22 lines \& 200\% & 188.99 & 0.853 \\
\hline \multicolumn{2}{|c}{} \\
\hline
\end{tabular}




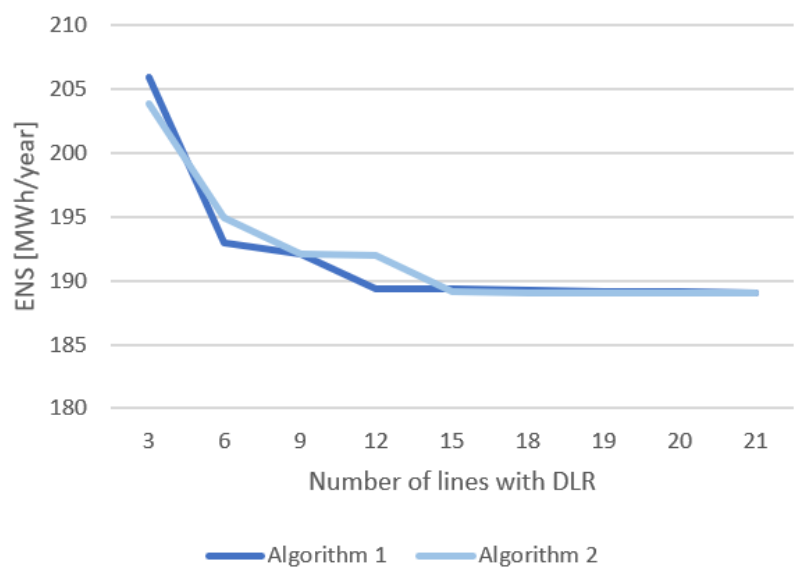

Fig. 7. Number of lines sensitivity

TABLE IV

VARIATION IN RESULTS BASED ON DLR IMPLEMENTED ON DIFFERENT NUMBER OF LINES

\begin{tabular}{|c|c|c|}
\hline Cases & $\begin{array}{c}\text { Total ENS } \\
{[\text { MWh/year }]}\end{array}$ & $\begin{array}{l}\text { Total SAIFI } \\
\text { [f/year/customer] }\end{array}$ \\
\hline Base case & 254.00 & 1.147 \\
Al. 1 \& 3 lines & 205.93 & 0.930 \\
Al. 1 \& 9 lines & 192.13 & 0.867 \\
Al. 1 \&15 lines & 189.31 & 0.855 \\
Al. 2 \& 3 lines & 203.88 & 0.9203 \\
Al. 2 \& 9 lines & 192.04 & 0.8669 \\
Al. 2 \& 15 lines & 189.12 & 0.8537 \\
22 lines & 188.99 & 0.8531 \\
\hline
\end{tabular}

\section{CONCLUSION}

The results presented in the previous sections have shown that a congested distribution system can present different results with the implementation of DLR compared with previous studies [17]-[19]. Due to the limits and constraints in OPF formulation, it is observed that limits other than thermal, such as voltage limits, are present in the system and can have a considerable impact on the results obtained.

The voltage level limits the effect of wind speed and ambient temperature on the results. Therefore, even though a line can theoretically carry more current, the bus voltage will rise or drop beyond the limit imposed. The same line of thought can also be applied to the results obtained by varying the imposed limitation for the capacity increase of the DLR. The results obtained for $140 \%$ or larger percentages are the same, which showed that the system is limited by additional factors other than line rating.

After increasing number of DLR lines, it is possible to conclude that the test system wouldn't significantly benefit by implementing DLR on more than 6-9 lines (30\% to $40 \%$ of the total lines). This shows that applying a monitoring system to all the conductors of a distribution system might not be the best strategy.

Conclusively, this study shows that DLR can improve the reliability and performance of a distribution system, but that the advantages are becoming less significant with a higher number of dynamically rated components. Further studies are necessary to assess better the positive impacts of this type of technology in different complex systems. The level of improvement from DLR seems to be related to the size, distribution of generation/loads and congestion of the system.

\section{ACKNOWLEDGMENT}

Authors would like to thank SweGRIDS, Swedish Energy Agency and Energiforsk AB Wind Research Program for project sponsorship.

\section{REFERENCES}

[1] S. Talpur, C. Wallnerstrom, C. Flood, and P. Hilber, "Implementation of dynamic line rating in a sub-transmission system for wind power integration," Smart grid and renewable energy, vol. 6, no. 8, pp. 233249, Aug 2015, qC 20150824.

[2] C. Wallnerstrom, P. Hilber, P. Soderstrom, R. Saers, and O. Hansson, "Potential of dynamic rating in Sweden," in 2014 International conference on probabilistic methods applied to power systems (PMAPS), Jul 2014, pp. 1-6.

[3] K. Morozovska, Dynamic Rating of Power Lines and Transformers for Wind Energy Integration, ser. TRITA-EECS-AVL. Stockholm, Sweden: KTH, Electromagnetic Engineering, 2018, no. 2018:37, QC 20180423.

[4] — "Dynamic rating with applications to renewable energy," Ph.D. dissertation, KTH, Electromagnetic Engineering, 2020, QC 20200109.

[5] D. M. Greenwood and P. C. Taylor, "Investigating the impact of realtime thermal ratings on power network reliability," IEEE Transactions on Power Systems, vol. 29, no. 5, pp. 2460-2468, Sep. 2014.

[6] K. Kopsidas, "Impact of thermal uprating and emergency loading of ohl networks on interconnection flexibility," in 2016 18th Mediterranean Electrotechnical Conference (MELECON), April 2016, pp. 1-6.

[7] IEEE Standard for Calculating the Current-Temperature Relationship of Bare Overhead Conductors (738-2012). USA: IEEE, 2013.

[8] J. Iglesias, G. Watt, D. Douglass, V. Morgan, R. Stephen, M. Bertin, D. Muftic, R. Puffer, D. Guery, S. Ueda, K. Bakic, S. Hoffmann, T. Seppa, F. Jakl, C. D. Nascimento, F. Zanellato, and H.-M. Nguyen, "Guide for thermal rating calculations of overhead lines," CIGRE, Tech. Rep., 2012.

[9] J. Lin and F. H. Magnago, "Optimal power flow," in Electricity Markets: Theories and Applications. Hoboken, NJ, USA: John Wiley Sons, Inc., 2017, pp. 147-171.

[10] R. Zimmerman, C. Murillo-Sanchez, and D. Gan, "Matpower-a matlab power system simulation package: User"s manual," 121997.

[11] R. Billinton and R. Allan, "Basic power system reliability concepts," Reliability Engineering and System Safety, vol. 27, no. 3, pp. 365-384, 1990.

[12] A. Chowdhury and D. Koval, Applications of Simple Reliability Models. IEEE, 2009. [Online]. Available: https://url2.cl/2r9Vu

[13] L. B. Tjernberg, Infrastructure Asset Management with Power System Applications, first edition.. ed. Boca Raton, FL: CRC Press, 2018.

[14] "Illinois center for a smarter electric grid (icseg)," 2019. [Online]. Available: https://url2.cl/8XPJF

[15] General Cable. (2013) Transpowr bare overhead conductors for transmission and distribution. [Online]. Available: https://url2.cl/6957L

[16] Swedish Meteorological and Hydrological Institute, SMHI. (2019) Ladda ner meteorologiska observationer. SMHI, 60176 Norrköping, Sweden. [Online]. Available: https://url2.cl/FAmhP, stationid $=133500$

[17] B. Banerjee, D. Jayaweera, and S. Islam, "Assessment of postcontingency congestion risk of wind power with asset dynamic ratings," International Journal Of Electrical Power Energy Systems, vol. 69, pp. 295-303, 2015.

[18] J. Fu, D. J. Morrow, S. Abdelkader, and B. Fox, "Impact of dynamic line rating on power systems," in 2011 46th International Universities' Power Engineering Conference (UPEC), Sep. 2011, pp. 1-5.

[19] P. M. Callahan and D. A. Douglass, "An experimental evaluation of a thermal line uprating by conductor temperature and weather monitoring," IEEE Transactions on Power Delivery, vol. 3, no. 4, pp. 1960-1967, Oct 1988. 